\title{
A teoria de Dworkin para a superação da tensão entre segurança jurídica e decisão justa
}

\author{
Eder Fernandes Monica ${ }^{1}$
}

\section{Resumo}

\begin{abstract}
Para Dworkin, a maneira de se superar a tensão entre segurança jurídica e decisão justa encontra-se na construção de uma teoria construtivista do direito que reduza a discricionariedade judicial por meio de decisões racionais baseadas no direito vigente. Para tal empreendimento, o autor faz críticas às teorias do direito de maior destaque na contemporaneidade, apontando as falhas e as soluções que pretende levar a cabo por meio de sua teoria alternativa.
\end{abstract}

Palavras-Chave: Segurança jurídica; Decisão justa; Teoria construtivista; Racionalidade da jurisdição.

\section{Introdução}

A teoria do direito de Dworkin pode ser entendida como a tentativa de garantir a segurança jurídica através da redução da discricionariedade judicial ao se defender a racionalidade da decisão do juiz, ou seja, a possibilidade de se chegar a uma única decisão judicial correta para cada caso. Ela visa evitar as falhas das propostas de solução realistas, positivistas e hermenêuticas, tentando esclarecer uma dupla exigência, que é a de produzir a segurança do direito e gerar a aceitabilidade racional das decisões.

Por um lado, o direito vigente garante a implementação de expectativas de comportamento sancionadas pelo Estado, o que gera segurança jurídica. Por outro, a legitimidade de tais expectativas assim estabilizadas apóia-se em processos racionais de normatização e de aplicação do direito, os quais tornam a norma jurídica merecedora de obediência. Tendo o direito a função socialmente integradora da ordem jurídica e de pretensão de legitimidade do direito, os juízos que são emitidos pelo tribunal têm que satisfazer simultaneamente as duas condições citadas: a da aceitabilidade racional e a da decisão consistente. Dworkin tentará superar esta tensão entre o princípio da segurança

1 Graduado em Direito pela Universidade Estadual de Londrina, mestrando em Direito Negocial pela mesma universidade. Artigo apresentado como requisito parcial de conclusão da disciplina de Teoria Geral do Direito, sob a supervisão da professora doutora Marlene Kempfer. 
jurídica e a pretensão de tomar decisões corretas através de uma reconstrução racional do direito vigente (HABERMAS, 2003, p. 245-246).

\section{As críticas e as soluções apontadas por Dworkin}

Dworkin empreende primeiramente uma crítica às três principais teorias do direito que tentam resolver o problema da racionalidade da operação jurisdicional em outros planos que não o apresentado pelo direito natural, que simplesmente subordinava o direito vigente a padrões suprapositivos (HABERMAS, 2003, p. 247).

O positivismo jurídico tentou garantir a consistência das decisões ligadas a regras e tornar o direito independente da política. Sublinhou o fechamento e a autonomia de um sistema de direitos, opaco em relação a princípios não jurídicos. Dessa maneira, resolve-se o problema da racionalidade dando primazia a um sistema de regras regulado por uma regra básica que decidirá a validade destas através de subordinações precisas. Privilegia-se a legitimação que se obtém por meio da legalidade, o "processo correto da positivação ou da resolução em detrimento da fundamentação racional do conteúdo de uma norma". As regras secundárias produzirão auto-referencialmente outras regras, que poderão ser determinadoras de comportamento. Já a corrente da hermenêutica jurídica vai contra a idéia da regra regulando a sua própria aplicação. A interpretação começa numa précompreensão valorativa, que estabelece uma relação preliminar entre norma e estado de coisas. Esta pré-compreensão, que inicialmente é difusa, torna-se mais precisa quando a norma e o estado de coisas constitue-se ou concretiza-se reciprocamente. Insere-se a razão no complexo histórico da tradição, sendo que a pré-compreensão do juiz é determinada através dos "topoi" de um contexto ético tradicional. Esse recurso a um "ethos" dominante foi alvo de crítica pelo realismo jurídico, que afirmou que a hermenêutica jurídica não oferece uma base convincente para a validade de decisões jurídicas, em meio a uma sociedade pluralista, na qual diferentes situações de interesses e de forças religiosas concorrem entre si. O fundamento da norma para os realistas encontra-se em elementos extra-jurídicos. Assim, a prática da decisão não é mais determinada internamente através da seletividade de procedimentos, do caso e do fundamento do direito. Então, não é possível fazer uma distinção clara entre direito e política e o direito passa a ser um instrumento do 
controle do comportamento a ser acionado para fins racionais (HABERMAS, 2003, p. 247251).

Dworkin critica o realismo por acreditar que há a possibilidade e é necessário que haja decisões consistentes ligadas a regras, que garantem uma medida suficiente de garantia do direito. Já contra o positivismo, afirma que com a ajuda da legitimação do conteúdo das decisões através de princípios, e não somente através de procedimentos, pode-se chegar a decisões corretas sem cair na discricionariedade judicial. E deve haver uma apropriação crítica da história institucional do direito, na qual a razão prática deixou os seus vestígios, o que se afasta em certa medida da noção de pré-compreensão da hermenêutica jurídica (HABERMAS, 2003, p. 252). Essas críticas iniciais vão ser o pano de fundo sob o qual Dworkin desenvolverá a sua teoria alternativa, tentando solucionar os problemas levantados. Sua teoria aborda o conceito de direito como um conceito interpretativo, não como um conceito semântico, o que privilegia a prática jurídica em detrimento de uma análise das regras que regulam o uso do termo "direito". O direito não é uma mera questão de fato, como defendem as versões conceituais do positivismo (PÉREZ, 2003, p. 352).

Dworkin, logo no prefácio do livro "O império do direito", ao expor sua intenção para com o livro, deixa claro que a sua proposta é a de que o raciocínio jurídico é um exercício de interpretação construtiva que tentará responder à questão de como poderá a lei comandar quando os textos jurídicos emudecem, são obscuros ou ambíguos (DWORKIN, 2003, prefácio). Mais especificamente, este é um livro sobre a divergência teórica no direito, sobre a divergência que há acerca do que seja direito (DWORKIN, 2003, p. 15). Este é um dos problemas centrais para a teoria de Dworkin.

Primeiramente, para explicar onde esta divergência se situa, Dworkin demonstra que os processos judiciais sempre suscitam, pelo menos em princípio, três tipos diferentes de questões. O primeiro tipo é o das questões de fato, que é mais fácil de ser percebida, pois quando há discordância quanto aos fatos concretos e históricos envolvidos na controvérsia sabemos sobre o que estão divergindo e como poderia ser resolvida a questão caso tal divergência não houvesse. O outro tipo é o das questões interligadas de moralidade política e fidelidade. Aqui as divergências ocorrem com freqüência, pois o debate quanto ao que é certo e o que é errado em termos morais é algo presente na vida das pessoas e pode ser levado ao tribunal sem causar maior problema. Entretanto, no terceiro tipo é que se 
encontra a dificuldade apresentada por Dworkin. Neste tipo estão as questões de direito, que freqüentemente são alvo de divergências pelos juristas ao discordarem sobre a lei que rege um caso. Eles realmente divergem quanto ao fundamento do direito, sobre o que o direito é de fato, criando uma divergência teórica, que é mais problemática. E assim restanos duas importantes questões: como conseguiríamos julgar quem tem o melhor argumento; e como saber se em um julgamento de um caso controverso o juiz, ao decidir, cria o direito ou simplesmente o encontra no ordenamento. A resposta seria clara se todos estivessem de acordo quanto ao que seja o direito, se não houvesse divergência teórica sobre os fundamentos do direito (DWORKIN, 2003, p. 5-10).

Dworkin antes de apresentar uma resposta para explicar de que tipo se trata a divergência teórica no direito e de criar e defender uma teoria particular sobre os fundamentos apropriados do direito, rejeita a visão de que o direito seja uma simples questão de fato e seja o que as instituições jurídicas decidiram no passado. Para o autor, esta visão do direito é mais uma "evasiva do que uma teoria". Tanto os conservadoristas, aqueles que acreditam dever sempre, a cada decisão, seguir o direito em vez de tentar aperfeiçoá-lo, quanto os que sustentam que os juízes devem tentar melhorar a lei sempre que possível baseiam-se, segundo Dworkin, nesta tese de que o direito vigente é uma simples questão de fato (DWORKIN, 2003, p. 10-15).

Rejeitar as questões de fato não significa negar que o direito seja um fenômeno social, um refletor das transformações e conflitos da sociedade. Entretanto, a prática do direito é argumentativa, o que o diferencia dos outros fenômenos sociais. Sua "complexidade, função e conseqüências dependem de uma característica especial de sua estrutura". Todos os envolvidos nesta prática argumentativa

compreendem que aquilo que ela permite ou exige depende da verdade de certas proposições que só adquirem sentido através e no âmbito dela mesma; a prática consiste, em grande parte, em mobilizar e discutir essas proposições (DWORKIN, 2003, p. 17).

Dworkin acredita que não cabe ao crítico apenas uma postura externa ao direito, mas este deve assumir a compreensão de um participante da prática social argumentativa, dispondo de sua opinião sobre o que considera boa ou má argumentação no âmbito dessa prática (DWORKIN, 2003, p. 17-18). Assim, ao se assumir o ponto de vista do participante, 
gera-se uma coerência narrativa entre os fatos debatidos. A suposição de que uma proposição é mais válida do que outra só pode ser feita dentro da atividade argumentativa. Um cético pode olhar para esta prática e dizer que ela se baseia em falsos fundamentos, mas a sua posição exterior não Ihe conferirá um peso argumentativo maior do que as dos participantes. Se o resultado da argumentação é válido ou não dependerá do fato de que esta atenda a algum propósito valioso e se o atende melhor do que o faria uma forma modificada da atividade (DWORKIN, 2001, p. 210-211).

Para Dworkin, há uma certa analogia entre a interpretação literária e a interpretação judicial. Tanto os críticos literários quanto os juízes precisam de uma teoria operacional ou, pelo menos, de um estilo de interpretação para compreender seus textos. Nesse sentido, os juízes precisam de uma teoria da legislação para que possam interpretar as leis. Essa teoria é necessária mesmo se não houver qualquer espécie de deficiência semântica, como ambigüidade ou vagueza das expressões. Mesmo que se adote uma teoria "literal" da interpretação, esta já é uma maneira de ver a lei, qual seja, a de atribuição de um significado acontextual aos termos da lei, que é independente de qualquer informação especial sobre o contexto de seu uso ou as intenções de seu autor (DWORKIN, 2003, p. 2122).

Para alguns filósofos do direito as regras de uso que empregamos ao trabalhar com o direito o liga ao fato histórico puro e simples. Da mesma maneira que seguimos as regras da linguagem que utilizamos, mesmo que não tenhamos plena consciência dela, podemos enunciar as regras do direito de alguma forma nítida e abrangente. Usamos os mesmos critérios factuais para formular, aceitar e rejeitar as afirmações feitas sobre a natureza do direito, entretanto, ignoramos o que são esses critérios. Mesmo havendo divergência quanto ao que seja o direito, há um pressuposto comum compartilhado de padrões que deve ser usado ao se buscar compreendê-lo. Para Dworkin, os filósofos que procuram certos critérios para avaliar as proposições jurídicas são os que, grosso modo, desenvolveram as chamadas teorias semânticas do direito. Assim, há uma pressuposição de que os advogados e juízes usam basicamente os mesmos critérios quando decidem sobre a verdade ou falsidade das proposições jurídicas, e que estão de acordo quanto aos fundamentos do direito. Não se sabe ao certo quais critérios são utilizados, pois eles estão ocultos e podem passar despercebidos (DWORKIN, 2003, p. 38-41). 
As teorias semânticas de mais destaque, segundo Dworkin, afirmam que ao se entender o direito como se fosse apenas uma questão de fato chega-se à conclusão de que a verdadeira divergência sobre a natureza do direito deve ser uma divergência empírica sobre a história das instituições jurídicas. São, dessa maneira, teorias positivistas, que diferem-se entre si sobre quais fatos históricos são cruciais. Para John Austin o direito é "uma questão de decisões históricas tomadas por aqueles que detêm o poder político". Já H. Hart, que reformulou esta idéia no seu livro "The concept of law", os verdadeiros fundamentos do direito encontram-se na "aceitação, por parte da comunidade como um todo, de uma regra mestra fundamental (regra de reconhecimento) que atribui a pessoas ou grupos específicos a autoridade de criar leis". Não basta somente a autoridade das pessoas que detêm o poder público, pois a comunidade deve aceitar, através de convenções sociais, um sistema de regras que outorga a tais indivíduos ou grupos o poder de criar leis válidas (DWORKIN, 2003, p. 41-42).

Hart elabora uma estratégia sofisticada de defesa de sua tese ao enfatizar a importância de se estabelecer uma distinção entre os usos padrões ou os usos intrínsecos da palavra "direito" e os usos limítrofes e nebulosos dessa mesma palavra. Concorda inicialmente com o argumento de que os juristas seguem basicamente a mesma regra para o uso da palavra "direito". Entretanto, isto não se dá em todas as ocasiões. Pelo fato destas regras não serem exatas, há casos nebulosos ou limítrofes nos quais as pessoas acabam discordando entre si. Alguns fundamentos são respeitados, mas cada um utiliza uma versão ligeiramente diferente da regra principal, e as diferenças tornam-se manifestas nestes casos específicos. Nesta "área de penumbra" manifestam-se os casos duvidosos, nos quais nem todas as pessoas seguem as mesmas regras (DWORKIN, 2003, p. 48-49).

Para a Escola Analítica, o importante era desenvolver um procedimento de identificação das normas jurídicas positivas através de alguns critérios supremos de dedução de normas que identificaria a validade e a pertinência destas ao ordenamento jurídico (CALSAMIGLIA, 1985, p. 161). Assim a fundamentação do direito surge de um esquema hierárquico unidirecional, pelo qual os enunciados de níveis distintos se fundamentam uns aos outros (PÉREZ, 2003, p. 368).

Por tentar desvencilhar-se de qualquer fundamento de validade suprapositivo, Hart estabelece a sua "regra de reconhecimento" a qual fará com que se decidam quais normas 
pertencem ou não ao direito vigente, permitindo subordinações precisas. Estabelecem-se, dessa maneira, dentro de um sistema jurídico autônomo, regras primárias, que determinarão o comportamento, e regras secundárias, que reproduzirão autoreferencialmente as normas. Assim, a validade das prescrições jurídicas será medida pela manutenção dos procedimentos juridicamente prescritos da normatização do direito. Há, nesse sentido, um privilégio ao processo correto de positivação em detrimento à fundamentação racional do conteúdo de uma norma. A "regra de reconhecimento" deve ser assimilada faticamente como parte de uma forma de vida histórica, conforme o costume. Hart explica isto utilizando-se do conceito de "jogo de linguagem", comparando a regra de reconhecimento à gramática de um jogo de linguagem. Há uma certa prática, que é tida como um fato e é aceita como auto-evidência cultural e suposta como válida pelos próprios participantes. Desse modo, a segurança jurídica é privilegiada e o fundamento das decisões dos casos nebulosos (hard cases) é solucionado recorrendo-se ao fato de que há uma imprecisão inevitável nas formulações da linguagem coloquial. Se o direito vigente não consegue, por meio de sua estrutura fechada, decidir precisamente tal questão, o juiz deve decidir conforme o seu próprio arbítrio (HABERMAS, 2003, p. 250-251). Este modelo positivista será posto à prova por Dworkin ao analisar os casos difíceis. Para o autor, a resposta dada pelo positivismo é insuficiente. Com o modelo de regras positivista, há uma integração do direito através de um conjunto finito de regras convencionais. Desse modo, aos casos difíceis não se apresenta, dentro do sistema, uma resposta adequada mediante a aplicação de normas, necessitando da intervenção livre do julgador (PÉ-REZ, 2003, p. 350).

A solução apontada por Dworkin é a distinção entre princípios e regras. Estas são normas concretas, já determinadas para uma aplicação específica; o que não acontece com os princípios, por serem gerais e carentes de interpretação. Ambos são mandamentos cuja validade deontológica exprime o caráter de uma obrigação. Entretanto, nenhum dos dois podem ser entendidos como preceitos de otimização porque isso suprimiria o seu sentido de validade deontológica. Tanto regras quanto princípios servem como argumentos na fundamentação de decisões, mas os valores posicionais de cada um na lógica da argumentação são diferentes. Em se tratando de regras há sempre um componente "se" que especifica condições de aplicação típicas da situação. De outro lado, os princípios ou surgem 
com uma pretensão de validade não-específica, ou são limitados em sua esfera de aplicação através de condições muito gerais, carentes de interpretação (HABERMAS, 2003, p. 258).

Com esta distinção, contra o positivismo Dworkin afirma a possibilidade e a necessidade de decisões corretas cujo conteúdo é legitimado à luz de princípios e não apenas formalmente, através de procedimentos (HABERMAS, 2003, p. 252). Enquanto um conflito entre regras é solucionado ao se introduzir uma cláusula de exceção ou ao se declarar uma das regras que entraram em conflito como inválida, um conflito entre princípios é solucionado estabelecendo entre os princípios conflitantes uma ordem transitiva que faz um princípio ceder lugar a outro, sem que isto fira a validade do outro. Desse modo, supera-se a visão positivista de um sistema fechado de regras específicas de aplicação de uma representação unidirecional do direito. Se neste modelo as colisões entre as regras geram uma indeterminação da situação jurídica que somente é superada decisionisticamente, com a distinção de Dworkin os princípios conseguem solucionar o problema do fechamento do sistema de regras e o do conflito de regras (HABERMAS, 2003, p. 258-259).

Ao se emancipar de fundamentos sagrados e se distanciar de contextos religiosos e metafísicos, o direito não se torna simplesmente contingente, como afirma o positivismo, mas nem está somente à disposição de objetivos do poder político, o que também afasta uma interpretação realista do direito. Há uma estrutura interna que permite uma reconstrução racional do direito, que se orienta por princípios que não são topoi historicamente comprovados extraídos exclusivamente do contexto tradicional de uma comunidade ética, como defendido pela hermenêutica jurídica. O ponto de referência de interpretação, para Dworkin, deve ultrapassar as tradições jurídicas consuetudinárias. É por isso que ele irá empreender um processo de interpretação construtiva do direito, postulando uma teoria do direito que reconstruirá racionalmente e conceitualizará o direito vigente (HABERMAS, 2003, p. 259-260). Frente a um caso difícil não cabe uma solução do direito natural, nem mesmo é possível admitir a discrição judicial. O que cabe aos juízes é buscar uma teoria jurídica que solucione o conflito e que seja a explicação e justificação mais coerente do direito positivo. Nesse sentido, não cabe mais fazer distinção entre uma ciência da legislação destinada aos filósofos e uma ciência da jurisprudência, a cargo dos juristas, como a feita pela Escola Analítica, pois as pontes que as separavam devem ser 
restabelecidas (CALSAMIGLIA, 1985, p. 162-163). Frente à concepção piramidal que correntemente se associa à idéia de fundamentação, na qual os enunciados de distintos níveis se fundamentam uns aos outros seguindo um esquema hierárquico unidirecional, Dworkin desenvolve um procedimento holista e coerente, que concebe a fundamentação como um "processo no qual se busca o apoio recíproco de todos os elementos dentro de uma trama de fundamentação na qual todos terão de responder por todos" (PÉREZ, 2003, p. 368).

Esse procedimento hermenêutico-crítico de Dworkin explica a racionalidade do processo de compreensão através da referência a um paradigma ou a um fim. A interpretação construtiva impõe um propósito a um objeto ou prática, tentando torná-los os melhores exemplos possíveis da forma ou do gênero aos quais se imagina que pertençam (DWOR-KIN, 2003, p. 63-64). O intérprete atribui uma intenção - isto é, um significado, ou um sentido - à pratica de que se trata, com o objetivo de mostrá-la em sua melhor perspectiva, dentro da forma ou gênero em que se supõe que pertence. A integridade é, para Dworkin, o significado ou intenção suprema do direito, e deve ser a guia valorativa a orientá-lo (PÉREZ, 2003, p. 366). É nesse sentido que o juiz deve encarar o direito, utilizandose desse processo de interpretação para poder chegar a uma decisão idealmente válida, compensando a suposta indeterminação do direito ao se apoiar numa "teoria" (HABERMAS, 2003, p. 261). Os casos difíceis são solucionados pelo juiz quando estes, ao aceitarem o ideal interpretativo da equidade, tentam encontrar em "algum conjunto coerente de princípios sobre os direitos e deveres das pessoas, a melhor interpretação da estrutura política e da doutrina jurídica de sua comunidade" (DWORKIN, 2003, p. 305).

Dworkin estabelece uma via para a tarefa do juiz, que é a do juiz racional que "leva os direitos à sério", que domina o "império do direito", que não se esquiva da tarefa de encontrar uma solução para todos os casos, mesmo os mais difíceis. Ele deve sempre buscar a unidade do direito, e fortalecê-la em cada um de seus juízos, por meio de uma coerência narrativa que melhor se adapta ao estado passado e presente do direito, e que estabeleça a melhor hierarquia dos princípios da moral política compartilhados pela comunidade em cada momento da história (OST, 1993, p. 180).

Com esta teoria pretensiosa Dworkin tentará satisfazer simultaneamente o princípio da segurança jurídica e a pretensão de legitimidade do direito. Tanto nos casos 
normais, quanto nos casos difíceis, as decisões poderão ser fundamentadas a partir do "contexto coerente do direito vigente racionalmente reconstruído". Com a idéia de coerência consegue-se estabelecer um meio-termo entre a verdade analítica obtida através da dedução lógica e o critério da não-contradição. A preocupação de Dworkin está em construir uma teoria do direito que não se fundamenta em uma ordem social baseada em princípios de justiça, mas que procure princípios e determinações de objetivos válidos que sirvam para justificar uma ordem jurídica concreta em seus elementos essenciais, dando coerência a todas as decisões tomadas em casos singulares (HABERMAS, 2003, p. 261-263).

Por isso há uma grande exigência sobre o "juiz Hércules", que deve conhecer "todos os princípios e objetivos válidos que são necessários para a justificação" e também deve possuir uma visão completa sobre o "tecido cerrado dos elementos do direito vigente que ele encontra diante de si, ligados através de fios argumentativos". Esses componentes não deixam que a teoria fique aberta à livre construção, pois fixam limites à interpretação construtiva do juiz. Quando o juiz Hércules é chamado à tarefa de construir uma ordem coerente de princípios as exigências da equidade o levam a analisar a história institucional de determinado sistema de direitos, classificando-a criticamente ao corrigir os erros possíveis. Assim, um sistema justo é possível quando é resultado de um processo continuado de aprendizagem. Há uma certa idéia sobre o direito que foi incorporada através da razão prática desenvolvida ao longo dos anos e que norteia a realização do direito. A esta concepção de direito é que Dworkin tentará sintetizar no conceito de direito como integridade. Para o autor esta concepção interpretativa é a melhor interpretação que pode ser dada à prática jurídica. Dessa forma, a proposta reconstrutiva do direito leva o juiz a alargar a sua teoria para que possa partir da moldura constitucional e passar pelas normas particulares do direito constitucional, simples leis e direitos consuetudinários, até decisões de princípios, comentários e outras fontes do direito. Mas tal teoria reconstrutiva deve ser seletiva o suficiente para permitir uma decisão correta, fazendo valer, dentro da ordem jurídica concreta, as pretensões exigidas para o caso analisado. Assim, há uma reconciliação entre passado e presente, entre história e justiça, pois há uma reconstrução racional da história institucional com vistas à aceitabilidade racional no presente, dissolvendo-se a tensão entre "originalidade judicial" e "história institucional" quando os juízes emitem novos 
juízos sem se oporem às decisões pretéritas e ao direito já estabelecido, pois simplesmente as refletem (HABERMAS, 2003, p. 263-264).

Essa seletividade em relação à história explica-se pelo fato de que a integridade não exige coerência de princípio em todas as etapas históricas do direito de uma comunidade. $\mathrm{A}$ coerência de princípio que se exige é mais horizontal do que vertical, pois o direito só se volta para o passado quando o enfoque contemporâneo assim determina. Não se recupera os ideais ou objetivos práticos dos políticos que criaram o direito anterior, mas justifica-se e organiza-se a prática atual através de "princípios suficientemente atraentes para oferecer um futuro honrado" (DWORKIN, 2003, p. 273-275).

Com este conceito de integridade Dworkin nega que o direito volta-se para o passado, como defende o convencionalismo, e também nega que o direito seja um instrumento pragmático, voltado para o futuro. As afirmações jurídicas são opiniões interpretativas que combinam elementos que se voltam tanto ao passado, quanto ao futuro. A prática contemporânea é uma política em processo de desenvolvimento, o que rejeita esta dicotomia entre passado e futuro, considerando inútil a questão de se os juízes descobrem ou inventam o direito, pois entende-se o raciocínio jurídico tendo em vista "que os juízes fazem as duas coisas e nenhuma delas" (DWORKIN, 2003, p. 271).

O sucesso da interpretação reconstrutiva só ocorrerá se a história, da qual uma ordem jurídica concreta surgiu, sedimentar algum fragmento de "razão existente". Para isto, Dworkin recorre ao conceito de "integridade", afirmando que todas as ordens jurídicas modernas apontam para a idéia do Estado de Direito. $O$ autor acredita que qualquer interpretação construtiva bem-sucedida de nossas práticas políticas como um todo reconhece a integridade como um ideal político distinto, que mostraria a melhor maneira de se ver as práticas de uma comunidade política (DWORKIN, 2003, p. 259-260). Neste ponto firme é que se manifesta o ideal político do reconhecimento recíproco dos cidadãos como livres e iguais. Os cidadãos exigem a proteção da integridade de sua convivência através de uma autocompreensão normativa das ordens do Estado de Direito inscritas na realidade constitucional, o que obriga os juízes a decidir o caso singular tendo em mente uma teoria do direito como um todo orientado por princípios (HABERMAS, 2003, p. 267-268).

Ao defender o direito como integridade, busca-se uma alternativa que vá mais além da dicotomia entre positivismo e jusnaturalismo. A "integridade" é um ideal ou virtude 
política que encerra em si a exigência de que os poderes públicos devem se conduzir não de modo arbitrário, mas de maneira coerente, ou seja, de acordo com um único sistema coerente de pautas de correção e de retidão, que Dworkin caracteriza nos princípios de justiça, equidade e devido processo. Mesmo que haja divergências na comunidade quanto ao que sejam esses princípios, não se pode afastar a exigência de coerência no trato com tais questões (PÉREZ, 2003, p. 350-353). Para Dworkin, esses princípios nortearam as proposições jurídicas fazendo-as verdadeiras se neles constam, ou se deles derivam, oferecendo a melhor interpretação construtiva da prática jurídica da comunidade (DWORKIN, 2003, p. 272). Na teoria do direito é que se centrará a circulação do sentido do direito. Este sentido não é privilégio de ninguém, nem do teórico, nem do juiz, nem do legislador. A circulação do sentido jurídico opera no espaço público. O direito existe antes dos juristas e haverá depois deles. Há uma inesgotável idéia do que seja o direito ou mesmo a justiça. Dentro desta perspectiva, os intérpretes atuais são os mais autorizados para interpretar o direito, o que não significa que detém o monopólio desta interpretação (OST, 1993, p. 181).

Há uma diferenciação no conceito de integridade quando este é visto pela ótica da legislação e pela ótica da jurisdição. Quando os políticos e os funcionários do Estado introduzem novas normas, ou reformam as normas vigentes, eles devem basear-se em um conjunto coerente de princípios que supõem-se estar na base de todo o material jurídico vigente. Já quando se analisa a integridade na prática judicial faz-se necessário que o juiz interprete o direito existente como se este tivesse sido criado por um único legislador, que atuou sob um esquema coerente de princípios (DWORKIN, 2003, p. 213). É neste segundo momento, o da prática judicial, que se manifesta de forma mais significativa a importância que tem a idéia de integridade para a teoria de Dworkin. Aos juízes cabe a tarefa de atuarem mantendo coerência com o direito em seu conjunto, como se o direito de uma comunidade fosse obra de um "legislador racional" e que houvesse para cada caso uma resposta correta (PÉREZ, 2003, p. 354-355). O princípio da integridade instruirá os juízes a identificar os direitos e deveres legais, até onde for possível, com base no pressuposto de que "foram todos legais, até onde for possível, com base no pressuposto de que "foram todos criados por um único autor - a comunidade personificada -, expressando uma concepção coerente de justiça e equidade" (DWORKIN, 2003, p. 271-272). 
Para Dworkin não deixar ao juiz a possibilidade de que este decida politicamente, o que levaria sua teoria a cair nas críticas dos realistas jurídicos, ele entende os direitos subjetivos como "trunfos" num jogo, no qual indivíduos defendem suas pretensões justificadas contra abusos que possam ser gerados por finalidades coletivas. Quando um direito é definido, ele não pode ser suplantado por nenhum fim social. Mas isto não é defender um direito subjetivo absoluto, porque cada direito somente coloca barreiras "ao cálculo do proveito e dos custos na realização de fins coletivos", sendo que estes são justificados a partir do igual respeito por cada um, que é a norma fundamental de Dworkin (HABERMAS, 2003, p. 252-253). O sentido deontológico dos direitos indisponíveis está no fato de eles terem um peso maior do que os bens coletivos e determinações de objetivos políticos (HABERMAS, 2003, p. 265). Este direito "mais forte" garante os direitos preestabelecidos e não permite leis retroativas, nem tolera poderes políticos paralelos aos órgãos representativos (CALSAMIGLIA, 1985, p. 163).

No mesmo sentido, para que as decisões não sejam arbitrárias, deve-se entender que os juízes assentam sua prática no trabalho jurisdicional construído ao longo de gerações. Esta história institucional traça o fio pelo qual o juiz deve pautar-se ao analisar o caso concreto. Devido ao dever institucional de resolver todos os casos litigiosos, o juiz pressupõe que sempre há uma solução - o que afasta a possibilidade de lacunas - e que só há uma decisão correta no sistema para o litígio - o que afasta a possibilidade de antinomias. A atividade jurisdicional está submetida a uma exigência institucional de justificação que extrai seus argumentos do direito vigente, o que faz do julgador um personificador teórico das pressuposições normativas em que se baseia esta atividade (PÉREZ, 2003, p. 355).

Ao tratar a questão da justiça, Dworkin não excluirá o nexo interno entre direito e política, pois a sua teoria do direito movimenta-se nos limites das ordens jurídicas concretas (HABERMAS, 2003, p. 243-244). A justiça seria para Dworkin uma instituição que interpretamos. Há uma ampla divergência sobre o que seja justiça e há também muitas teorias a seu respeito. Pode ser que não tenhamos nenhuma formulação eficaz do conceito de justiça, mas mais interessante que isto é que compartilhamos a mesma percepção préinterpretativa dos limites aproximados da prática da qual nossa imaginação deve exercitarse. Esta percepção é responsável para distinguir quais concepções de justiça rejeitamos por não aceitá-las como plausíveis. É tarefa dos filósofos, ou até sociólogos, desvendarem os 
paradigmas que hoje utilizamos para analisar qual seja a concepção de justiça com a qual trabalhamos. É paradigmático para nós que tanto a punição de inocentes, quanto a escravidão ou roubar dos pobres para favorecer os ricos sejam coisas injustas. A maioria de nós rejeitaria de imediato qualquer concepção que aceitasse um desses exemplos (DWORKIN, 2003, p. 89-93).

Na idéia de integridade como virtude há uma característica que permite explicar de modo satisfatório a conexão necessária e ao mesmo tempo a diferenciação entre o direito e moral. Há uma relação interna entre estes dois âmbitos, pois a justificação da prática jurídica não se satisfaz apenas com o apelo a meras convenções, mas também a princípios que entram no processo de justificação como princípios morais. Os juízes não podem julgar com base em seus próprios princípios e, por isto, recorrem aos princípios do sistema que atuam como princípios morais genuínos (PÉREZ, 2003, p. 356). Dworkin, para sustentar a sua teoria dos direitos, recorre a uma razão prática que está incorporada na história e que, de certa forma, a atravessa. Assim, afirma que há pontos de vista morais relevantes na jurisprudência devido ao fato de que o direito positivo já assimilou conteúdos morais (HABERMAS, 2003, p. 252-253). Estes conteúdos morais também estão inseridos numa conceituação interpretativa, não semântica. As discussões sobre o conteúdo dos conceitos morais, ou políticos, não podem realizar-se mediante critérios lingüísticos, mas tem de ser substanciadas em processos de interpretação construtiva impregnadas também de juízos de valor. Estas diversas concepções interpretativas morais e políticas com relação à igualdade, à liberdade, à democracia etc. são interpretações destes conceitos, atualizações e contextualizações do que há de "bom", de valioso nos ideais representados por estes conceitos (PÉREZ, 2003, p. 366).

\section{Conclusão}

Desse modo, Dworkin constrói uma teoria do direito que se desvincula de qualquer preocupação maior com uma teoria da justiça, pois acredita que o ordenamento atual já carrega em si vários direitos que foram fruto de um longo processo histórico e que os aplicadores do direito têm em mão material suficiente para empreender uma reconstrução racional do direito se se basearem no conceito de integridade. Se tais pressupostos forem atendidos, supera-se a tensão que ocorre entre segurança jurídica e a necessidade de 
decisões justas. A tentativa de Dworkin, apesar de ter recebido muitas críticas devido ao seu alto teor de Idealismo, objetivou solucionar os problemas que até então não tinham sido resolvidos pelos modelos tradicionais do direito. Com a redução da discricionariedade judicial ao se oferecer meios ao juiz para tal reconstrução do direito, geraria um aumento da segurança jurídica ao mesmo tempo em que se produziriam decisões aceitáveis e justas, baseadas no próprio direito vigente.

\section{Referências}

CALSAMIGLIA, Albert. Por que es importante Dworkin? Doxa, n. 02, 1985.

DWORKIN, Ronald. Uma Questão de Princípio. São Paulo: Martins Fontes, 2001. . O Império do Direito. São Paulo: Martins Fontes, 2003.

HABERMAS, Jürgen. Direito e Democracia: entre facticidade e validade. 2. ed. Rio de Janeiro: Tempo Brasileiro, 2003. v. 1.

OST, François. Júpiter, Hércules, Hermes: Tres modelos de juez. Doxa, n. 14, 1993.

PÉREZ. Uma filosofia para erizos: una aproximación al pensamiento de Ronald Dworkin. Doxa, n. 26, 2003.

VEGAS, Jesús Luis Castillo. Tres modelos posibles de relación entre la seguridad jurídica y la justicia. Crítica-Revista de Filosofia, v. 9, n. 29/30, abr./out. 2004. 
